\title{
O QUADRANTE DE RUETSAP E A ANTI-CIÊNCIA, TECNOLOGIA E INOVAÇÃO
}

\section{Francisco Radler de Aquino Neto}

Instituto de Química, Universidade Federal do Rio de Janeiro, Cid. Univ. Ilha do Fundão, 21949-900 Rio de Janeiro - RJ

\begin{abstract}
RUETSAP'S QUADRANT AND ANTI-SCIENCE, TECHNOLOGY AND INNOVATION. The concept of research and the controversy among classical models for $\mathrm{C}, \mathrm{T} \& \mathrm{I}$, outdated by the development of knowledge and Post-modern society needs were revisited through the (3) Quadrants advanced by Donald Stokes in the mid-nineties. The scientific community to fit into these Quadrants was faced with many difficulties and reacted by issuing pseudo-facts, accepted by under-prepared technocrats as viable justifications for conducting research in face of these new paradigms. In a poor country full of contrast and needs such as Brazil, this attitude satisfies the bureaucracy and academic elite, but frustrates government and society, that do not get, in the expected measure, the benefits of their commitment with the Teaching, Research and Extension Sectors mainly embedded in the Public University system. An extension, in fact a contradictory approach, to Pasteur's Quadrant, is proposed to characterize this situation: The Syndrome of Ruetsap's Quadrant.
\end{abstract}

Keywords: Pasteur's Quadrant; Stokes Quadrants; Ruetsap's Quadrant.

\section{INTRODUÇÃO}

Donald Stokes, prematuramente falecido antes da edição de seu livro Quadrante de Pasteur ${ }^{1}$, deixou um legado fantástico para a racionalização desapaixonada dos embates entre as correntes de defensores de posições, tanto antagônicas quanto excludentes, com relação ao foco desejável para o fomento à pesquisa. Fazem parte desse embate as intermináveis discussões sobre a indissociabilidade da pesquisa, extensão e ensino nas Universidades, em especial sobre como estabelecer um equilíbrio dinâmico que seja reflexo das vocações institucionais, e, como preservar esse equilíbrio, mesmo que assimétrico, sem deixar que a prevalência de uma das tendências prejudique ou elimine as demais.

Como será desenvolvido a seguir, Stokes procurou classificar as pesquisas em três categorias interpenetrantes visando: avanço científico; aplicação prática e, avanço científico almejando aplicação. Tentou assim, escapar da dicotomia simplória pura $v s$ aplicada ou básica $v s$ aplicada e demonstrar que há um sem número de situações em que a pesquisa é simultaneamente fundamental e aplicada (Figura 1a).

Essa abordagem tem sido utilizada em modelos para gestão de financiamento à $\mathrm{C}, \mathrm{T} \& \mathrm{I}$ tanto no $\mathrm{CNPq}$ como na FAPESP. Nessa última, inclusive, a alocação de recursos chegou a ser explicitamente avaliada segundo esse modelo ${ }^{2,3}$.

\section{OS TRÊS QUADRANTES (PRÓ-ATIVOS) PROPOSTOS POR STOKES}

A proposta de racionalização de Stokes ${ }^{1}$ envolve, portanto, três quadrantes: Bohr, caracterizando o avanço da ciência pela ciência; Edison, a investigação para a invenção prática e, Pasteur, onde essas duas vertentes coexistiriam na concepção da pesquisa (Figura 1a).

\section{Expansão da proposta de Stokes}

A conceituação de Stokes poderia ser expandida de duas maneiras para representar a realidade atual.

A primeira, se reconhecermos que os quadrantes poderiam ser

*e-mail: radler@iq.ufrj.br a)

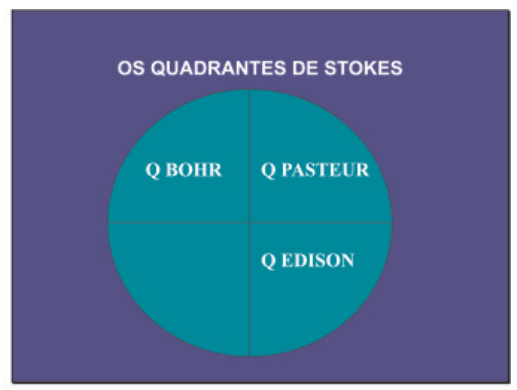

b)

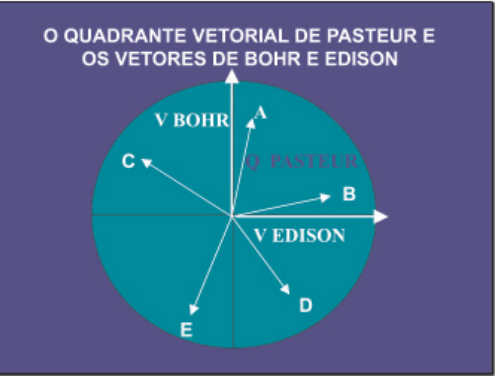

Figura 1. a) Versão original dos Quadrantes de Stokes ${ }^{l}$. b) Proposta de manutenção do Quadrante de Pasteur e redução a vetores dos Quadrantes de Bohr e Edison. Pontos A e B representam gradações de conteúdo básico e aplicado nas pesquisas. Os pontos $C$ e $D$ ilustram a falta de sentido prático dos Quadrantes de Bohr e Edison

vetoriais (Figura 1b). Assim sendo, uma gradação entre pesquisa básica e aplicada estaria contida no Quadrante de Pasteur (por ex., o ponto A com cunho mais básico; ponto B com cunho mais aplicado). Os Quadrantes de Bohr e Edison perderiam o sentido tornando-se Vetores de Bohr e de Edison. Afinal, nesse espaço vetorial não faria sentido imaginar que uma pesquisa básica no Quadrante de Bohr fosse necessariamente uma antipesquisa aplicada por ser composta por um vetor negativo no eixo de Edison (ponto C, Figura 1 b) ou vice-versa (ponto D, Figura $1 b$ ).

Por outro lado seria possível imaginar o Quadrante de Ruetsap, formado pela combinação de gradações de antipesquisa básica e antipesquisa aplicada (ponto E, Figura 1b).

$\mathrm{O}$ espaço que define as categorias de pesquisa ficaria, portan- 
to, caracterizado por dois vetores, os quais por sua vez definiriam apenas dois quadrantes relevantes, o de Pasteur e o de Ruetsap. Na região positiva (Figura 2 a) os vetores de Bohr e Edison caracterizariam pesquisas relevantes de cunho fundamental e aplicado, respectivamente, e o Quadrante de Pasteur envolveria pesquisas constituídas por gradações desses aspectos. Na região negativa (Figura 2a) estariam reunidas as pseudo-ciências e aplicações apenas formais, simplesmente fruto de uma extrapolação inconseqüente dos resultados para justificar uma aplicação ilusória.

Assim, o vetor de Bohr seria inspirado na curiosidade, o de Edison no uso, o Quadrante de Pasteur nas necessidades sociais e o de Ruetsap nas necessidades individuais (Figura 2b).

O cuidado de Stokes em não abordar essas situações indesejáveis, ao omitir o quarto Quadrante de suas considerações, poderia ser explicada por uma preocupação de não associar um eventual viés negativo ao conceito de pesquisa. Infelizmente essa possibilidade se faz cada vez mais presente nas atividades de pesquisa em desenvolvimento. A comunidade científica, ao invés de evitar tocar nesse assunto para não despertar os críticos ao fomento à pesquisa, deve enfrentar o problema que tem sido a maior causa da eficácia limitada da produção científica mundial, em especial a brasileira.

a)

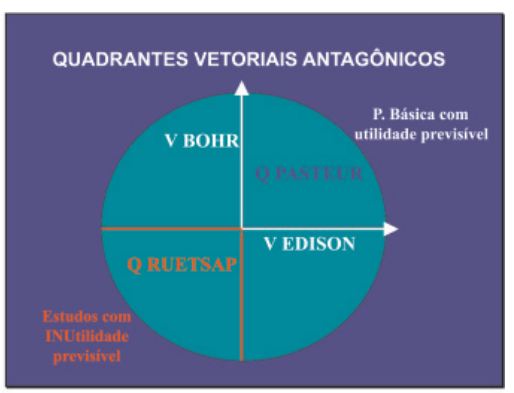

b)

VETORES \& QUADRANTES VETORIAIS

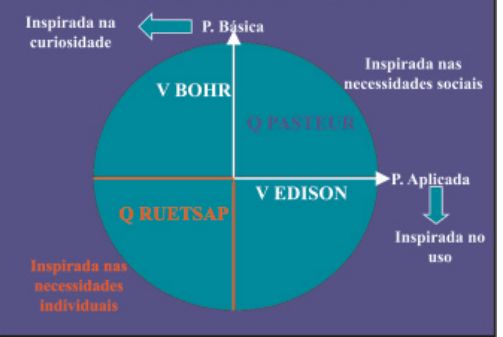

Figura 2. a) O Quadrante de Pasteur e o Quadrante de Ruetsap . b) Destaque para o Quadrante de Ruetsap

\section{A falácia do acaso e da serendipiticidade}

Uma corrente da Academia procura justificar a pesquisa pela pesquisa, com base em descobertas fortuitas. A serendipiticidade ("serendipity") seria um mecanismo de novas descobertas onde, no decorrer ou como consequiência de um trabalho de pesquisa, inovações seriam obtidas. É um fato que "atirar no que viu e acertar no que não viu" pode ocorrer. Os defensores desse método de investigação levantam como sua maior bandeira a criação do "World wide web" (www), em 1990, pelo Centro Europeu de Pesquisas Nucleares (CERN) em Genebra, Suíça ${ }^{4}$. Essa inovação, que provocou a maior revolução tecnológica da história da humanidade, resultou de um trabalho acadêmico para comunicação de resultados na área de física nuclear.

O que essas pessoas não enfatizam é o fato de que a descoberta resultou de um trabalho dedicado, com objetivo claro e metas úteis cientificamente. Como foi executado por pesquisadores competentes, seu desdobramento a outras aplicações desenvolveu-se naturalmente.
Portanto, não resultou de uma pesquisa pela pesquisa que se em nada resultasse teria sido um completo desperdício.

A pergunta que se deve fazer é: qual é a proporção de casos de serendipiticidade de sucesso, em relação ao sucesso de pesquisas projetadas para atingir uma meta obviamente relevante do ponto de vista do avanço científico?

Estar alerta para a oportunidade de serendipiticidade é uma coisa, trabalhar de forma aleatória, sem um foco no resultado e sua utilidade, esperando que uma aplicação científica ou prática caia do céu, é outra. Não há justificativa ética nem econômica para essa segunda forma de atuar.

\section{Objetividade da proposta de pesquisa e sua utilidade}

A Academia tem horror às palavras utilidade, praticidade, aplicabilidade, quando relacionadas à pesquisa. É claro que a inovação necessita de liberdade, criatividade e flexibilidade de ação. O que não é justificável é confundir essas atitudes com irresponsabilidade, descompromisso com o retorno dos investimentos e falta de objetivos mensuravelmente alcançáveis.

Em nome da tão decantada liberdade para pensar e pesquisar criouse uma total dissociação entre alocação de meios/recursos para pesquisa e retorno dos mesmos. Nem mesmo o retorno acadêmico stricto sensu através de publicações de qualidade é considerado, o que diria se almejar atingir metas que contribuam para o avanço científico ou tecnológico, ou mitigação de problemas sociais e econômicos.

Desmistificando essa "bandeira" da liberdade para criar atrás da qual se escondem irresponsabilidade, descaso, comodismo, e incompetência, o que se deve objetivar são pesquisas que acrescentem informações relevantes ao conhecimento; sejam elas puramente acadêmicas ou diretamente aplicadas, mas essencialmente úteis.

Portanto, contrariamente ao que essa escola conservadora e corporativista procura propalar, a utilidade da pesquisa não é um aspecto menor, pejorativo até, na concepção de projetos. É sua única razão de ser, além de representar oportunidade de retorno financeiro. Se o trabalho de fato é útil, alguém comprará a idéia e financiará o projeto: sejam órgãos federais, estaduais e municipais de fomento, ou empresas e indivíduos. Com o virtual desaparecimento do mecenato para as ciências essa é a única forma de realizar pesquisas, cada vez mais dependentes de instalações sofisticadas e equipamentos e insumos de custo elevado.

\section{Necessidade de resultados práticos e tentativas de indução da pesquisa por organismos de fomento}

Com a escassez de recursos para pesquisa e aumento das necessidades da sociedade, o sistema de financiamento à pesquisa passou a induzir pesquisas com retorno prático. Isso novamente exacerbou a cisão entre os defensores da pesquisa básica e da aplicada. Ao mesmo tempo, deflagrou uma reação da comunidade acadêmica, que passou a atrelar à qualquer pesquisa sua "aplicação".

Essa prática chegou a extremos na comunidade científica brasileira, envolvendo tanto os pesquisadores, com suas propostas sem a menor ligação com a realidade, como os financiadores que se deixaram ludibriar por essa atitude, porque em sua transitoriedade pelo sistema, podiam mostrar os objetivos maravilhosos que estavam recebendo apoio financeiro, todos sabendo, no íntimo, que esses jamais seriam atingidos.

\section{Causas da Síndrome de Ruetsap}

O Quadro 1 reúne algumas causas para o aparecimento da Síndrome de Ruetsap e suas conseqüências. 
Quadro 1. Causas da Síndrome de Ruetsap externas à Academia e suas consequiências

\section{Causas externas}

- Despreparo da sociedade: dificuldade em associar P\&D + Educação com benefícios sociais e econômicos;

- descompromisso das elites: os segmentos mais preparados ("elite intelectual") têm discurso pró-pesquisa e prática voltada a seus interesses;

- carência da população: a maioria da população almeja necessidades básicas e a pesquisa está elitizada e sem retorno garantido;

- insensibilidade política: ou despreparo da classe política para relacionar P\&D + Educação com benefícios sociais e econômicos presentes e futuros, associado ao oportunismo voltado ao atendimento do "clamor" popular;

- sucessivas crises econômicas: descompasso entre o parque industrial instalado, mão-de-obra disponível e escassez de recursos;

- desmantelamento da máquina estatal: corrupção, corrosão e desmobilização por "downsizing" e,

- soberba da comunidade de C\&T: despreparo para enfrentar o desafio de atender aos anseios da sociedade e comunicar-se efetivamente com a população.

\section{Conseqüiências}

- escassez de recursos para C\&T + Educação;

- pressão governamental para melhoria da razão custo/benefício e,

- demanda vultosa de recursos para oferta pífia acirra canibalismo na comunidade de C\&T + Educação.

A pressão insuportável sobre a comunidade de $\mathrm{P} \& \mathrm{D}+$ Educação através de diretrizes de fomento realçando utilidade (no caso utilidade prática mesmo, não apenas a científica) levou a práticas então desconhecidas no mundo ético da Academia: tráfico de influência na seleção de temas de P\&D; critérios espúrios de julgamento de propostas a editais; evolução de indicadores de desempenho baseada no perfil dos proponentes dos mesmos e, adequação grosseira dos proponentes aos novos paradigmas de fomento à pesquisa com aviltamento dos objetivos; insensatez ou má fé? e, oportunismo e ambição.

A crise que se instalou no sistema de Pós-graduação \& Pesquisa fez surgir o que de pior tem essa comunidade. Esse lado negro da Academia adormecido ou anestesiado pelos anos de bonança financeira, tomou conta das relações Academia - financiadores, criando-se uma relação mutuamente cínica onde uns propõem desenvolver maravilhas e outros aceitam essas propostas pelo seu valor de face, sem questionar de modo eficiente sua validade.

Alie-se a isso a prática de pesquisadores solicitarem recursos sem um estudo real de economicidade, salgando os pedidos; dos órgãos de fomento pulverizarem seus recursos alocando muito menos que o solicitado, inviabilizando a proposta; do governo de contingenciar recursos, cortar e retardar sua liberação para prazos incompatíveis com o bom andamento da pesquisa.

Nessas circunstâncias só resta aos pesquisadores fingir que pesquisam e aos avaliadores fingir que os objetivos foram atingidos.

Então, instalado o faz de conta, vale mais quem for mais criativo na proposta de objetivo de maior visibilidade econômica e social. Não importa o embasamento da proposta que indique que o objetivo será atingido em um prazo razoável.

Predomina, portanto, a Síndrome Ruetsap, com pesquisas inúteis travestidas de grandes avanços científicos, tecnológicos e sociais.

Como reverter este processo? Para recolocar o trem nos trilhos é preciso que as pesquisas sejam ÚTEIS na sua essência e conse- qüentemente o seu desenrolar resulte, de fato, nos objetivos propostos.

É necessário recuperar a indissociabilidade entre a execução do trabalho e o objetivo a ser alcançado. Encerrar a prática de colocar objetivos "marqueteiros" para um desenvolvimento que se sabe jamais atingirá os objetivos.

Para reorientar as propostas de P\&D a solução é simplória na forma, mas complexa no conteúdo: é preciso sempre elaborar "o porquê" de realizar uma pesquisa, descendo ao detalhe do "porquê" realizar cada experimento.

O desperdício de tempo e recursos materiais, equipamentos sub-utilizados, abundância de resultados, são práticas a serem evitadas (impedidas?), além do mais quando não levam a nada de inovador.

\section{Inovação e a evolução do "porquê pesquisar"}

Além da pressão financeira mencionada anteriormente, verifica-se que a comunidade científica não se apercebe que o conhecimento acumulado transforma temas candentes em resultados descontextualizados.

Há 30 anos novas técnicas analíticas permitiram descobrir a composição dos materiais. Assim sendo, determinar a estrutura de uma molécula com Raios-X de monocristal era um feito épico e publicação relevante, bem como de dados de análise térmica diferencial e calorimetria. Sínteses e transformações para compreender a reatividade de funções orgânicas, uma necessidade para o desenvolvimento de novas moléculas. A Química de produtos naturais queria ter um mínimo de conhecimento molecular dos organismos vivos.

Há 10 anos, genoma, proteoma, química combinatória, tipagem de DNA eram coisas fantásticas.

Hoje, metaboloma, biodiversidade molecular e modificação genética são a bola da vez.

Mas, publicações no Journal of Thermal Analysis and Calorimetry agora são consideradas como de categoria inferior; a tipagem de DNA é efetuada em qualquer esquina para teste de paternidade; transformações químicas só têm visibilidade se resolverem um problema concreto de interesse sintético e, qual o sentido de analisar uma nova espécie ou variedade de planta per se?

O mundo científico mudou, mas quantos de nós continuamos nesse passado de glórias?

Hoje, o foco é inovação, não a palavra vazia, mas a clara determinação (e condição) de atingir metas inovadoras. Atenção! Isso é diferente de novidade. Analisar uma nova espécie vegetal, um sedimento jamais analisado, o efluente de uma fábrica não estudada são novidades, mas não inovações. Essa é uma percepção de difícil absorção prática, mas fundamental para tirar a comunidade científica da mesmice.

Alia-se a isso a crise financeira permanente, obrigando o cientista moderno a ser um Empreendedor lato sensu. Isto é, estabelecendo um Planejamento Estratégico com indicadores mensuráveis, um Planejamento Operacional exequiível no prazo definido e Análises Críticas que avaliem constantemente o status dos indicadores (respostas objetivas e mensuráveis) face às metas propostas (o "porquê").

Motivos para a má escolha do tema (o "porquê"), por ex., são a tradição do grupo de pesquisas levando ao comodismo, conformismo, inércia; interesse pessoal (o quanto de fato é crucial?) e, falta de análise cuidadosa da necessidade real da pesquisa, as quais levam à sua superficialidade.

O foco inadequado é outra causa de temas irrelevantes: atuar em áreas já desbravadas (repetições e ampliações de pesquisas realizadas); seguir diretrizes ultrapassadas (institucionais, governa- 
mentais e de fomento); produzir grandes quantidades de dados, mas descontextualizados.

Exemplos dessa prática em algumas áreas do conhecimento que empregam a Química serão apresentados a título ilustrativo. Afinal, após tantos anos dessa prática, a própria comunidade científica tem dificuldade de identificá-la.

\section{Seleção de temas para pesquisa}

Nunca é demais enfatizar a objetividade na seleção de temas de pesquisa. Essa deveria derivar de uma retroanálise onde, a partir de uma meta definida, as etapas para atingi-la seriam progressiva e hierarquicamente estabelecidas. Infelizmente, como comentado anteriormente, a prática usual é a de estabelecer metas ambiciosas de grande visibilidade, mas realisticamente dissociadas das etapas que poderiam levar a elas. No outro extremo, ainda é corrente propor novidade como inovação.

No meio do caminho ficam aqueles que não se apercebem de que a evolução do conhecimento obliterou o impacto de grandes pesquisas do passado, às quais executadas hoje representam mera repetição ou derivação do que já foi executado.

Essas três atitudes comuns às propostas de pesquisas resultam no acúmulo de informação à procura de interessados. O oposto do pretendido por uma investigação científica a qual deveria ser obter dados para responder às questões que desafiam o conhecimento existente.

Alguns exemplos ilustrativos serão apresentados com o objetivo de auxiliarem em uma auto-avaliação de nossas atitudes. Todos serão inicialmente apresentados como de grande impacto empregando a estratégia atual de colocar "adereços" nas propostas para que o público leigo "compre" as idéias.

Floresta Amazônica, biodiversidade, drogas anticâncer e a Química de Produtos Naturais (QPN). Há quem possa ser contrário ao fomento da QPN, quando aborda a análise molecular de plantas da Amazônia e tem por justificativa a declaração de que "a biodiversidade está ameaçada, as plantas amazônicas podem conter moléculas milagrosas para cura de todos os males, essas moléculas serão perdidas com o desaparecimento de espécies nativas, a Amazônia é brasileira podendo ser perdida devido ao abandono das autoridades"?

Assim passa-se à análise sistemática de "novas" espécies da Amazônia; eis a "inovação". Sem contextualizar essa pesquisa é inútil, pois se trata de investir enorme capital humano e material para, no escuro, analisar plantas que podem não apresentar nenhuma novidade molecular ou pior, que mesmo apresentando alguma molécula nova, esta não apresente propriedades interessantes. Para piorar, é muito provável, como em geral analisam-se amostras de apenas um indivíduo, que as moléculas identificadas sejam únicas daquele instante na vida daquele indivíduo, não sendo representativas de algo que possa ser reproduzido ${ }^{5}$.

Essa coleta sistemática de dados não é assistida pelo foco atual de fomento, não sendo classificável como pesquisa científica e, muito menos, inovação. No entanto, essa criação de bancos de dados pode vir a ser relevante para aplicações futuras, como veremos mais adiante, sob a ótica de "serviços científicos".

Por outro lado, testar novas técnicas ${ }^{6}$ ou novos conceitos, como por ex., aspectos de ecossistemática, dariam razão concreta para o esforço ser classificado como de pesquisa.

Exploração e produção de petróleo. A prospecção geoquímica de petróleo empregando biomarcadores ${ }^{7,8}$ é essencial para a descoberta de novas províncias petrolíferas. Assim justifica-se a análise de quaisquer moléculas orgânicas presentes em sedimentos, pois "poderão vir a se tornar biomarcadores importantes". Novamente a falta de contexto faz com que a pesquisa seja fadada a não chegar a lugar algum. É indispensável que esse trabalho se desenvolva em um Sistema Petrolífero específico onde a correlação entre os elementos relevantes, por ex., as rochas potenciais geradoras de petróleo, as vias de migração do óleo gerado e as "trapas" onde o óleo é acumulado pudessem ser identificados através dos biomarcadores, permitindo a correlação entre elas e a distribuição das moléculas. Essa informação sobre a dinâmica de geração e acumulação do petróleo orienta os trabalhos de perfuração e produção nessa bacia.

Meio ambiente externo e interno. Uma das áreas que mais sofre com a abordagem Ruetsap é a de "Meio Ambiente", provavelmente pela conscientização da sociedade para seus impactos nas suas vidas e das gerações futuras. Mede-se, portanto, tudo, sem se chegar a nenhuma conclusão nova.

Qual o sentido de avaliar quimicamente a poluição da Baia de Guanabara, Rio Tietê, Baia dos Todos os Santos, Rio Amazonas, Rio Paraíba, Lagoa dos Patos ou a qualidade do ar do Rio, São Paulo ou Brasília, tomando-se duas amostras, ou 10 que sejam, ao ano? Que esses locais estão poluídos já sabemos. Um número tão reduzido de amostras e sem uma racionalização das variáveis que transportariam e acumulariam os poluentes nos pontos de coleta não poderia em sã consciência servir para diagnóstico do problema.

Com relação à qualidade do ar externo, a coleta de dados só se justifica no âmbito de amplo contexto de monitoração e correlação com fontes e processos de distribuição dos poluentes. Curiosamente, um tema recente, o Meio Ambiente Interior ${ }^{9}$, ainda justifica muitas pesquisas de determinação dos poluentes característicos de ambientes internos (escritórios, casas, escolas) em diferentes situações geográficas. Uma vez esgotada esta "curiosidade" inicial, esses trabalhos também perderão a conotação de pesquisa ou inovação. Sua continuidade dependerá de se agregar outros aspectos que necessitem do conhecimento dos poluentes presentes em uma determinada situação para que sejam compreendidos.

Bioquímica, Biologia Molecular, Biotecnologia. A bioquímica aplicada à medicina também passou por esta evolução. Simplesmente determinar a estrutura do DNA; bioequivalência de fármacos; resíduos em alimentos; perfil hormonal, ocorrência de aminoácidos, ácidos orgânicos e outras substâncias em fluidos biológicos não mais se constitui em pesquisa. Embora seu impacto no dia-a-dia seja determinante (como teste de paternidade, barateamento de medicamentos, diagnóstico precoce de enfermidades, respectivamente) os conceitos inovadores já foram estabelecidos.

Novamente, esses serviços de alto valor agregado só se constituiriam em pesquisa genuína caso associados a situações onde a resposta ainda não tenha sido estabelecida. Por ex., na determinação de fraudes ${ }^{10}$, avaliação do abuso de drogas, estudo de novas formulações, pesquisa de novas doenças metabólicas, etc.

Esses mesmos argumentos se aplicam além da Química Analítica, à Química Sintética, de transformações e de materiais e à Físico-Química.

O porquê de sintetizar determinada substância ou preparar determinado "novo" material, bem como caracterizar certas propriedades físico-químicas de sistemas, não resistirá a uma análise crítica de sua relevância, caso não haja um arcabouço lógico realista para a utilização desses avanços.

Simplesmente declarar, sem fundamentação clara e objetiva, que há possibilidade de se gerar um fármaco revolucionário, um material de propriedades inusitadas ou descobrir-se um novo estado da matéria, não pode ser aceito como justificativa para "pesquisa".

\section{Serviços científicos: documentação científica do conhecimento}

A polarização entre os três quadrantes de Pasteur e a necessidade de se chegar a uma inovação de fato relegou à estratégia de 
Ruetsap a catalogação de informações novas cujo conteúdo inovador não é efetivo.

Nessa categoria enquadram-se atividades importantes de acumulação de informação, como por ex., os constituintes químicos de plantas e dos demais seres vivos, características metabólicas de indivíduos sãos e com diferentes moléstias, composição de ar, rios, mares, solos, correlação de materiais e suas propriedades, reavaliação de processos industriais, etc. Isto é, um conhecimento que descontextualizado não pode ser considerado pesquisa e, em muitos casos, mesmo contextualizado refere-se mais a trabalhos rotineiros que inovadores.

Não há espaço para essas atividades nos sistemas atuais de fomento à pesquisa, mas elas podem representar importante avanço tecnológico. Não necessariamente uma inovação tecnológica, mas um produto tecnológico.

Dois exemplos claros dessa abordagem são a síntese combinatória e a triagem de produtos naturais, ambos visando a descoberta de novos fármacos. Ambas abordagens simplesmente submetem as moléculas sintetizadas ou extratos a baterias de ensaios de atividade biológica. A partir daí, alvos para novos medicamentos podem ser definidos.

Outro caso típico é o monitoramento ambiental para criar uma base histórica de acompanhamento da evolução da qualidade do meio ambiente, que permita propor políticas para impedir sua degradação. $\mathrm{O}$ investimento para o controle ambiental deve refletir a gravidade do problema, que só pode ser acessada com séries históricas de medição.

Tentar enquadrar esses trabalhos de pura chance ou acumulação de dados como pesquisa inovadora é atitude de Ruetsap. Por outro lado é importante não os considerar e conduzir como "Serviços Técnicos" rotineiros. Em função da complexidade dos sistemas a serem documentados e das análises a serem efetuadas, esses trabalhos revestem-se de grande sofisticação, devendo ser considerados como "Serviços Científicos". A diferenciação entre Serviços Técnicos e Serviços Científicos não tem sido enfatizada no planejamento do fomento às bases do desenvolvimento $\mathrm{C}, \mathrm{T} \& \mathrm{I}$. A estrutura próxima à de pesquisa tem levado os Serviços Científicos a serem apresentados como pesquisa, principalmente por não haver financiamento para esse tipo de atividade! Além disso, não são serviços que possam ser vendidos, pois a utilidade das bases de dados está mais voltada para avaliações de longo prazo ou para permitir o estabelecimento de séries históricas que possam subsidiar políticas públicas. Portanto, a iniciativa privada não tem interesse em aplicar recursos com essa finalidade. Por outro lado, a falta de um mecanismo formal de fomento resulta em três atitudes questionáveis:

- apresentação do Serviço Científico como pesquisa (Quadrante de Ruetsap);

- realização do Serviço Científico como Serviço Técnico rotineiro, sem a qualidade necessária para que os resultados apresentem a qualidade e robustez necessárias para seu uso em séries históricas ou bancos de dados e,

- descontinuidade ou pulverização dos Serviços Científicos, resultando em séries históricas e bancos de dados incompletos ou incongruentes o que limita (quando não inviabiliza) sua utilidade.

Os órgãos de fomento deveriam se capacitar para avaliar propostas nesse sentido e, assim, passar a exigir seriedade na formulação de solicitações, mas garantindo as duas formas independentes de fomento: para a pesquisa stricto sensu e para Serviços Científi- cos de levantamentos de dados desde que sua utilidade seja nitidamente explicitada, bem como as necessárias continuidade e abrangência de execução.

\section{CONCLUSÕES}

A prática atual tornou irrelevante o debate sobre pesquisa pura, aplicada, tecnológica, inovadora, ou fundamental. Qualquer pesquisa em Química deve ser útil. Útil no sentido de acrescentar novos conhecimentos ou materiais aos já existentes. Novas informações devem ser entendidas como "serviços científicos", cuja realização não é necessariamente de categoria inferior às pesquisas, como normalmente se considera e nem são desprovidos de objetivos (mais remotos) inovadores, desde que realizados em um arcabouço definido com a amplitude, abrangência e profundidade necessárias.

A falta de visão da importância dos "Serviços Científicos" e conseqüente falta de mecanismos de fomento levam seus responsáveis a apresentar os mesmos como pesquisa. Ainda mais que os profissionais que militam nessas áreas são identificados como "pesquisadores".

Esse é o primeiro passo em direção ao Quadrante de Ruetsap. $\mathrm{Na}$ ânsia de justificar os seus trabalhos, pesquisadores passam a empregar chavões para que suas propostas se enquadrem nas diretrizes dos organismos de fomento. Embora convictos de que a possibilidade de alcançar os objetivos ambiciosos das diretrizes seja remotíssima, por razões de sobrevivência são capazes de omitir esse aspecto e pular da proposta à conclusão prevista, mas inatingível.

Há de se alertar para aspecto ainda mais preocupante, relacionado a propostas que são completamente destituídas de sentido, mas travestidas de "pesquisas" pela associação a objetivos tão pomposos quanto enganosos. Essas seriam as propostas Ruetsap stricto sensu que precisam ser rejeitadas pelo sistema. É preciso reconhecer que nem sempre este comportamento é derivado de má fé. Verifica-se em muitos casos que resulta de deficiência de formação ou desconhecimento por parte dos envolvidos de como transformar uma idéia, ou vontade de pesquisar, em uma utilidade teórica ou prática.

É, portanto, indispensável, em nome da evolução científica, tecnológica e da inovação, da preservação da ética científica e da qualidade da Educação Superior e, em especial no caso brasileiro, da racionalização do emprego de recursos escassos, estabelecer um debate sobre esses comportamentos visando sua identificação e eliminação.

\section{REFERÊNCIAS}

1. Stokes, D.; Pasteur's Quadrant. Basic science and technological innovation, Washigton, D. C., 1990.

2. Anônimo; Pesquisa Fapesp 2000, 60, 2.

3. Anônimo; Pesquisa Fapesp 2001, 61, 14

4. Salmeron, R. A.; Pesquisa Fapesp 2004, 106, II.

5. Pereira, A. S.; Amaral, A. C. F.; Silva, M. A.; Aquino Neto, F. R.; Z. Naturforsch., C: J. Biosci. 2001, 56, 357.

6. Pereira, A. S.; Siqueira, D. S.; Elias, V. O.; Simoneit, B .R. T.; Cabral, J. A.; Aquino Neto, F. R.; Phytochemistry 2002, 61, 711.

7. Aquino Neto, F. R.; Quim. Nova 1984, 7, 79.

8. Peters, K. E.; Walters, C. C.; Moldowan, J. M.; The biomarker guide, $2^{\text {nd }}$ ed., Cambridge: UK, 2004, vols. 1 e 2.

9. Aquino Neto, F. R.; Rev. BRASINDOOR 2001, 5, 14.

10. Marques, M. A. S.; Damasceno, L. M. P.; Pereira, H. M. G.; Aquino Neto, F. R.; Caldeira, C. M.; Dias, B. F. P.; Rosane, D. G. V.; Amoêdo, N. D.; Volkweis, R. O.; Viana, R. O. V.; Rumjanek, F. D.; J. Forensic Sciences 2005, 50, 387. 